Marcus J. Schultz

\section{Postoperative pneumonia or ventilator-induced lung injury?}

Accepted: 5 December 2014

Published online: 20 December 2014

(C) Springer-Verlag Berlin Heidelberg and ESICM 2014

A reply to these comments can be found at doi:10.1007/s00134-014-3610-3.

Dear Editor,

Recently, in your journal, Wan et al. [1] reported on the incidence and outcome of postoperative ARDS in kidney transplant patients. During the study period, 72 out of $1,369(5 \%)$ patients developed ARDS within 1 week after surgery: 10 patients with mild, 38 with moderate, and 24 patients with severe ARDS. The authors claim that all cases of ARDS were by pneumonia, though the diagnostic criteria used were not reported. However, too loose diagnostic criteria for pneumonia (e.g., not using bronchoalveolar lavage fluid) could lead to incorrect classification of infectious ARDS, consequently underestimating the incidence of non-infectious ARDS [2].

Postoperative pulmonary complications, including postoperative ARDS, are associated with high morbidity and mortality [3]. Several randomized controlled trials suggest that so-called 'protective' ventilation strategies during general anaesthesia for surgery, which use low tidal volumes with or without high levels of positive end-expiratory pressure, prevent postoperative pulmonary complications [4-6]. One could hypothesize that postoperative ARDS in the study by Wan [1] could have been the consequence of the use of 'non-protective' ventilator settings during kidney transplant surgery; i.e., they should be seen as "ventilatorinduced lung injury' [7].

In this context, it would be very interesting to know how patients were ventilated during surgery, and whether there was an association between intraoperative ventilator settings, like tidal volume size and the level of positive end-expiratory pressures, and the occurrence of ARDS in the postoperative phase.

\section{References}

1. Wan Q, Zhang P, Ye Q et al (2014) Acute respiratory distress syndrome in kidney transplant recipients. Intensive Care Med. doi: 10.1007/s00134-014-3590-3
2. Baudouin SV (2001) Ventilator induced lung injury and infection in the critically ill. Thorax 56(Suppl 2:ii):50-57

3. Serpa Neto A, Hemmes SN, Barbas CS et al (2014) Incidence of mortality and morbidity related to postoperative lung injury in patients who have undergone abdominal or thoracic surgery: a systematic review and meta-analysis. Lancet Respir Med 2(12):1007-1015

4. Futier E, Constantin JM, Paugam-Burtz C et al (2013) A trial of intraoperative low-tidal-volume ventilation in abdominal surgery. N Engl J Med 369(5):428-437

5. Ge Y, Yuan L, Jiang X et al (2013) [Effect of lung protection mechanical ventilation on respiratory function in the elderly undergoing spinal fusion]. J Cent South Univ Med Sci 38(1):81-85

6. Severgnini $P$, Selmo G, Lanza $C$ et al (2013) Protective mechanical ventilation during general anesthesia for open abdominal surgery improves postoperative pulmonary function. Anesthesiology 118(6):1307-1321

7. Slutsky AS, Ranieri VM (2013) Ventilator-induced lung injury. New Engl J Med 369(22):2126-2136

M. J. Schultz (-)

Department of Intensive Care, C3-415, Academic Medical Center, University of Amsterdam, Meibergdreef 9, 1105 AZ Amsterdam, The Netherlands e-mail: marcus.j.schultz@gmail.com

M. J. Schultz Laboratory of Experimental Intensive Care and Anesthesiology, Academic Medical Center, University of Amsterdam, Amsterdam, The Netherlands 